\title{
Evaluation of a collagen matrix in a mandible defect in rats submitted to the use of bisphosphonates ${ }^{1}$
}

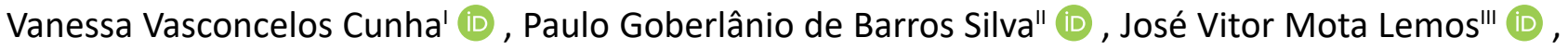 \\ Joyce Ohana Lima Martins ${ }^{\mathrm{IV}}$ (D), Milena Oliveira Freitas ${ }^{\mathrm{V}}$ (D) , Rafael Linard Avelar" (D) \\ ' Fellow Master degree, Academic Master in Dental Sciences, School of Dentistry, Centro Universitário Christus \\ (UNICHRISTUS), Fortaleza-CE, Brazil. Substantive scientific and intellectual contributions to the study. \\ "Professor, Division of Oral and Maxillofacial Surgery, School of Dentistry, UNICHRISTUS, Fortaleza-CE, Brazil. \\ Critical revision, final approval. \\ II'Dentist, School of Dentistry, UNICHRISTUS, Fortaleza-CE, Brazil. Statistics analysis, manuscript preparation. \\ IV Dentist, School of Dentistry, UNICHRISTUS, Fortaleza-CE, Brazil. Manuscript preparation. \\ ${ }^{\vee}$ Dentist, School of Dentistry, UNICHRISTUS, Fortaleza-CE, Brazil. Acquisition, analysis and interpretation of \\ data; technical procedures.
}

\begin{abstract}
Purpose: To assess the effect of a collagen matrix (Mucograft ${ }^{\circledR}$ ) on the inflammatory process in a semi-critical experimental defect model in rats treated with bisphosphonates.

Methods: Eighteen Wistar rats were randomly divided into three groups: saline (CG), alendronate (ALD) $5 \mathrm{mg} / \mathrm{kg}(\mathrm{AG})$ or zoledronic acid (ZA) $0.2 \mathrm{mg} / \mathrm{kg}(\mathrm{ZG})$. ALD was administered orally for 10 weeks and ZA was administered intravascularly on days 0,7 and 14 and 49. On day 42, a $2 \mathrm{~mm}$ defect was created and filled with Mucograft ${ }^{\circledR}$ collagen matrix. The contralateral side was filled with a clot (control side). The animals were euthanized 70 days after the beginning of the experiment and the hemimandibles were radiographically and histologically (counting of empty osteocyte lacunae (\%), apoptotic (\%) and total osteoclasts, neutrophil and mononuclear inflammatory cells) analyzed. The variables were submitted to ANOVA/Bonferroni and t test (parametric data) ( $p<0.05$, GraphPad Prism 5.0).

Results: Significant bone repair occurred in the groups treated with Mucograft ${ }^{\circ}$. High number of total inflammatory cells and neutrophils cells were showed in $A G(p=0.026$ and $p=0.035)$ and $A Z$ groups $(p=0.005, p=0.034)$ on the control sides associated with delayed bone repair and the presence of devitalized bone tissue in AG and ZG on the Mucograft ${ }^{\circledR}$ side.
\end{abstract}

Conclusion: Mucograft ${ }^{\circledR}$ collagen matrix attenuated the inflammatory process in a mandible defect in rats submitted to the use of bisphosphonates ( $A G$ and $Z G$ ).

Key words: Collagen. Osteonecrosis. Biphosphonates. Bone and Bones. Rats. 


\section{- Introduction}

Medication-associated osteonecrosis of the jaw (ONJ) is a serious complication in patients on drugs that inhibit bone resorption, such as bisphosphonates (BPs) and anti-RANKL monoclonal antibodies (i.e., denosumab ${ }^{1-3}$ ). Since the first report in $2003^{4}$, an increasing number of ONJ cases have been reported ${ }^{2}$.

Bisphosphonates are drugs that inhibit bone resorption, suppressing recruitment and activity of osteoclasts, thus reducing their useful life. These drugs are used as part of the chemotherapeutic treatment of bone cancers, such as multiple myeloma and metastatic disease in breast, prostate and lung cancer, which significantly impact patients' quality of life ${ }^{5}$.

Despite their proven effectiveness as anti-resorptive drugs, a devastating side effect has been documented in data published in recent years ${ }^{3,6}$. Patients diagnosed with bisphosphonates-related osteonecrosis of the jaw (BRONJ) usually present alveolar bone exposurenecrosis, purulent secretion, pain, intraoral or extraoral edema and fistulas. Severe cases can lead to pathological fractures, oroantral fistulas and severe infections of the head and neck ${ }^{7}$.

The propensity to bisphosphonates-related osteonecrosis of the jaw (BRONJ) may be due to several anatomical and physiological factors. Bisphosphonates tend to be concentrated in the mandibular bone, and not in other skeletal sites, because they are placed in significant bone remodeling $\operatorname{sites}^{8-10}$. Thus, the forces of the masticatory function can easily induce microfractures that also require remodeling. In addition, unlike other skeletal sites, after surgery or trauma, the wound may be continuously exposed to more than 500 different species of microorganisms, resulting in high susceptibility to contamination and infection ${ }^{10}$.

One form of treatment of ONJ is to remove necrotic bone and apply surgical wound dressings ${ }^{2}$. One way to promote regeneration and cover exposed bone is to use collagen membranes such as Mucograft ${ }^{\circledR}$. The type I and III porcine collagen membrane is a totally resorbable 3D matrix that promotes the proliferation of fibroblasts and induces the production of extracellular matrix ${ }^{11}$. According to Ramalingam et al. ${ }^{11}$ histological studies have shown a decrease in the inflammatory infiltrate and absence of multinucleated giant cells.

However, in view of the pro-osteogenic properties of the Mucograft ${ }^{\circledR}$ collagen matrix and possible use to control/treat ONJ, the objective of this study was to evaluate the effect of bone remodeling using the Mucograft ${ }^{\circledR}$ collagen matrix in a model of osteonecrosis of the jaw induced by ALD and ZA

\section{- Methods}

This study was approved by the Animal Ethics Committee of the Centro Universitário Christus under protocol number 040/17 and performed in the laboratory of the same institution.

Eighteen Wistar rats (Rattus norvegicus) with a body mass between 180 and 220 grams were used. The animals were kept in appropriate cages, six animals per cage, individually numbered by a tail marking and kept in 12-hour light-dark cycles with water and food ad libitum.

\section{Experimental protocol}

The animals were randomized and equally divided into the following three experimental groups: control group (CG), group treated with alendronate $(A G)$ and group treated with zoledronic acid (ZG).

After anesthesia using xylazine $(20 \mathrm{mg} / \mathrm{kg})$ and ketamine $(80 \mathrm{mg} / \mathrm{kg})$, the animals in the control group were treated weekly with $0.1 \mathrm{ml} / \mathrm{kg}$ of saline solution by gavage and intravenously. The animals in the alendronate group were treated weekly with $0.1 \mathrm{ml} / \mathrm{kg}$ of alendronate $70 \mathrm{mg}\left(\mathrm{EMS}^{\circledR}\right.$, Brasilia-DF, Brazil), $6 \mathrm{mg} / \mathrm{kg}$ by gavage and $0.1 \mathrm{ml} / \mathrm{kg}$ of sterile saline solution (penile access). The animals in the ZG were weekly administered $0.1 \mathrm{ml} / \mathrm{kg}$ of sterile saline and $0.2 \mathrm{mg} / \mathrm{kg}$ of ZA (Eurofarma ${ }^{\circledR}$, Itapevi-SP, Brazil) was administered intravascularly, in accordance with a previously published protocol [8]. In this group, $0.1 \mathrm{ml} / \mathrm{kg}$ of ZA was administered on days 0,7 and 14 , $0.1 \mathrm{ml} / \mathrm{kg}$ saline solution was administered on days 21 , 28,35 and 42 (day of the surgical procedure), $0.1 \mathrm{ml} / \mathrm{kg}$ ZA was administered on day 49 , and $0.1 \mathrm{ml} / \mathrm{kg}$ solution saline was administered on days 54 and 63 . The animals were weighed weekly to assess body mass gain (final mass: per initial mass $\times 100 \%$ ) (Table 1$)$. The animals were euthanized by an overdose of xylazine $(50 \mathrm{mg} / \mathrm{kg}$ ) and ketamine (Syntec ${ }^{\circledR}$, Santana de Paraiba-SP, Brazil) $(150 \mathrm{mg} / \mathrm{kg})$ on day 70 .

The dose of ZA and ALD was obtained by converting the recommended dose for the treatment of bone metastases in humans as described by SILVA et al. ${ }^{8}$. Since the dose of alendronate recommended for the treatment of osteoporosis in an adult person weighing approximately $75 \mathrm{~kg}$ is $70 \mathrm{mg} /$ week ( $0.95 \mathrm{mg} / \mathrm{kg} /$ week), as suggested by the Food and Drug Administration, the estimated dose for rats was $6 \mathrm{mg} / \mathrm{kg} /$ week (human dose $\left.(\mathrm{mg} / \mathrm{kg})^{*} 6.2\right)$.

\section{Surgical procedure}

The surgery took place one month after the last dose of ZA (D42), under anesthesia with xylazine 
$(20 \mathrm{mg} / \mathrm{kg})$ and ketamine $(80 \mathrm{mg} / \mathrm{kg})$, following the protocol by for the creation of calvary defects, adapting it to the mandibular ramus.

After trichotomy was performed on the mandibular ramus, the dermis was disinfected using three applications of $1 \%$ chlorhexidine digluconate spray (Neba-Sept ${ }^{\circledR}$, Panvel, Londrina-PR, Brazil), incision in the mandibular angle using a number 15 scalpel blade (Solidor $^{\circledR}$, Sao Paulo-SP, Brazil) on a scalpel handle (Bad Parker Golgran ${ }^{\circledR}$, Sao Caetano do Sul-SP, Brazil) and the masseter muscle was dissected using Seldin Golgran ${ }^{\circledR}$. After visualization of the mandibular ramus, a circular bicortical defect was prepared using a 2-mm drill

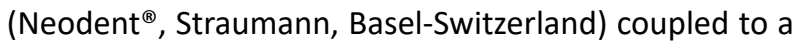
Neogrug XT Plus Neodent ${ }^{\circledR}$ engine rotating at 1100 rpm for approximately 10 seconds under irrigation with saline water (Fig. 1).

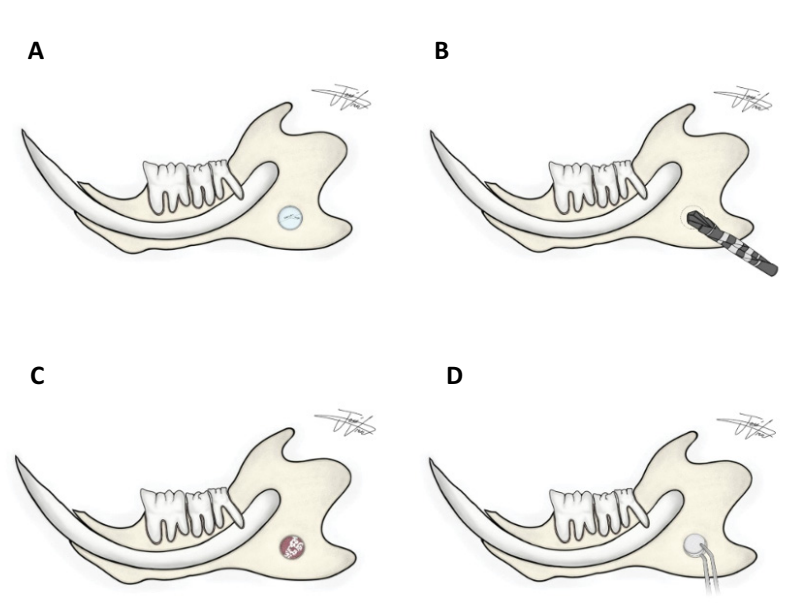

Figure 1 - A. Schematic model of the semi-critical defect in the mandibular ramus of Wistar rats submitted to the administration of sterile saline, ALD or AZ. B. Schematic drawing of the drill throws into the bone defect. C. Drawing of the bone defect filled with a clot.

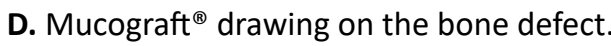

The defect was made bilaterally, and the left side was closed with a 4-0 suture needle (SK140, Procare ${ }^{\circledR}$ Rio de Janeiro-RJ, Brazil) using the single-suture technique after filling it with an autogenous clot. The right side was filled with the Mucograft ${ }^{\circledR}$ collagen matrix in the size corresponding to the surgical defect and closed with suture thread (needle thread for suture Procare ${ }^{\circledR}$ Seda, 4-0, SK140) using the same technique. Morphine $0.25 \mathrm{mg} / \mathrm{kg}$ was administered by gavage every 12 hours for three days to reduce postoperative pain.

\section{Digital radiographic analysis}

The hemimandibles of all groups were radiographed using a conventional X-ray device (63Kvp, $8 \mathrm{~mA}$, DabiAtlante $^{\circledR}$, Ribeirao Preto-SP, Brazil) coupled to the digital image capture device (Digora, $\mathrm{Kavo}^{\circledR}$, JoinvilleSC, Brazil). The parallel radiographic technique (long cone) used an SE localizer. The hemimandibles were positioned parallel to the radiographic film and the focus-film distance was $10 \mathrm{~cm}$. Exposure time was established at 0.18 seconds, setting the function of the digital periapical radiograph for the upper anterior dental arch (13-23). The hemimandibles were qualitatively evaluated by three oral radiologists (kappa $=0.873)$ that investigated and described the aspects of healing and signs of BRONJ (Fig. 2).

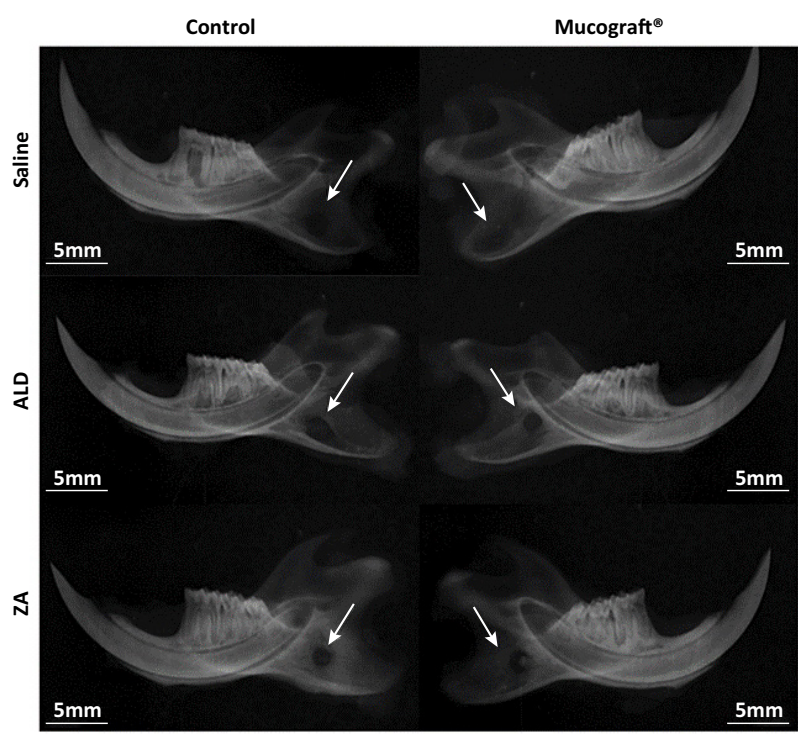

Figure 2 - Radiographic analysis of the mandible of rats treated with saline, ALD or AZ and the semi-critical mandibular defect model treated with or without Mucograft ${ }^{\circledR}$.

\section{Laminae and histopathological analysis}

The hemimandibles were decalcified in 10\% EDTA solution ( $\mathrm{pH} 7.3 ; \mathrm{NaOH}, \mathrm{PA})$ for 30 days and kept in suspension. After decalcification, the material was included in paraffin, cut at a thickness of $3 \mu \mathrm{m}$, and stained with hematoxylin-eosin for further qualitative analysis using conventional light microscopy.

The lamina were qualitatively described and 10 fields were photographed at 400x magnification for subsequent counting of viable and empty osteocyte 
lacunae to calculate the percentage of empty osteocyte lacunae, viable and apoptotic osteoclasts to calculate the percentage of apoptotic osteoclasts, neutrophil polymorphonuclear and mononuclear cells ${ }^{8}$ (Fig. 3).

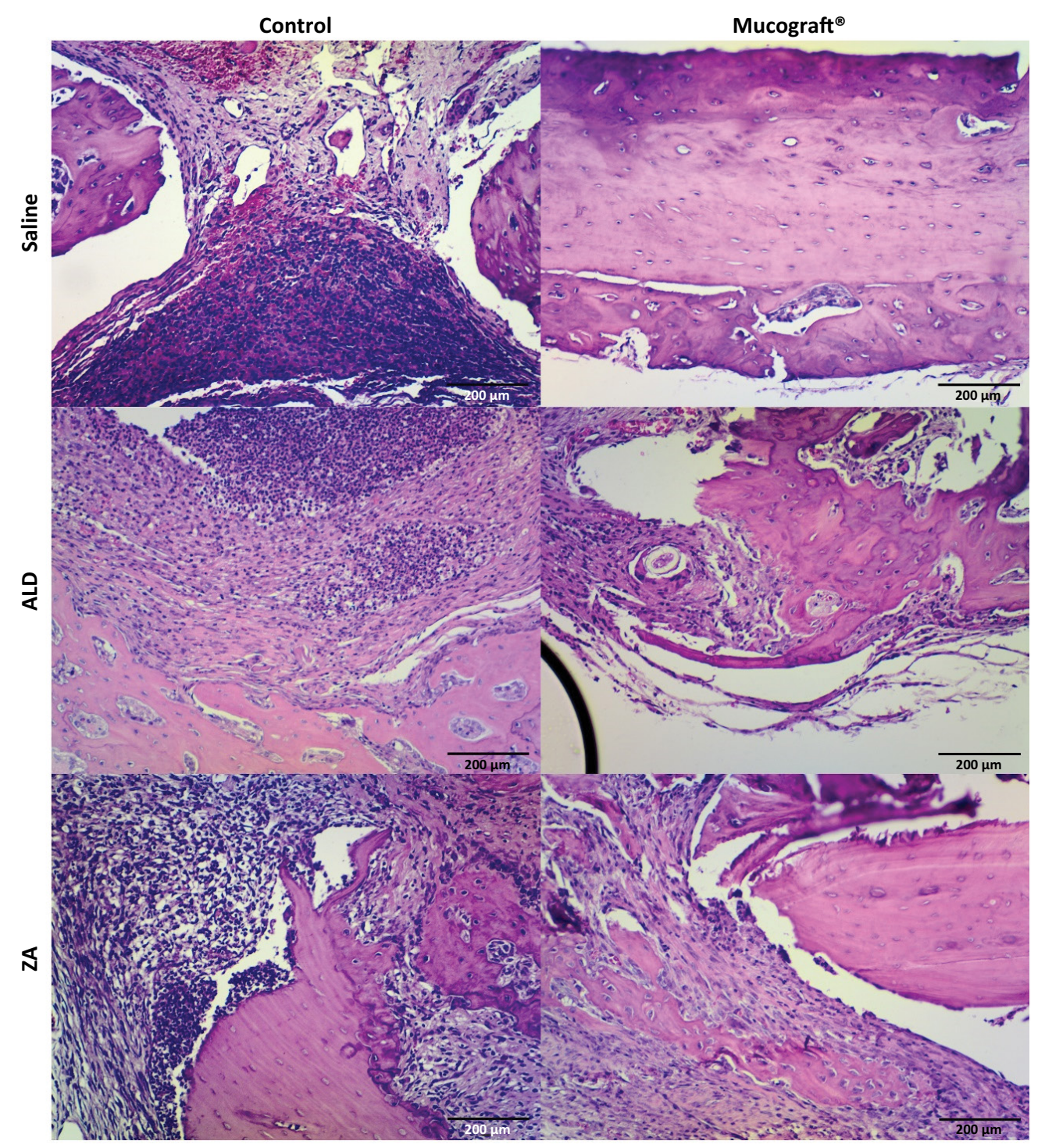

Figure 3 - Microscopic analysis of the mandible of rats treated with saline, ALD or AZ and the semi-critical mandibular defect model treated with or without Mucograft ${ }^{\circledR}(\mathrm{HE}, \mathrm{x} 40) .{ }^{* *}$ Inflammatory infiltrate; VB: vitalized bone; NO: necrotic bone.

\section{Statistical analysis}

The variables were submitted to KolmogorovSmirnov tests for normality, expressed as mean \pm SD, and analyzed using one-way or two-way ANOVA followed by the Bonferroni post-test (parametric data) or Kruskal-Wallis followed by Dunn's post-test (non-parametric data). All analyses were performed using the GraphPad Prism ${ }^{\circledR} 5.0$ statistical software and the significance index adopted for all evaluations was $\mathrm{p}<0.05$. 


\section{- Results}

Evaluation of body mass gain in rats undergoing mandibular defect model and treated with bisphosphonates

All animals presented body mass gain throughout the experiment. One week after the surgical procedure, there was a significant weight reduction on day 49 , followed by weight gain until day $70(p<0.001)$. There were no significant differences between the three experimental groups throughout the study $(p=0.740)$ (Fig. 4).

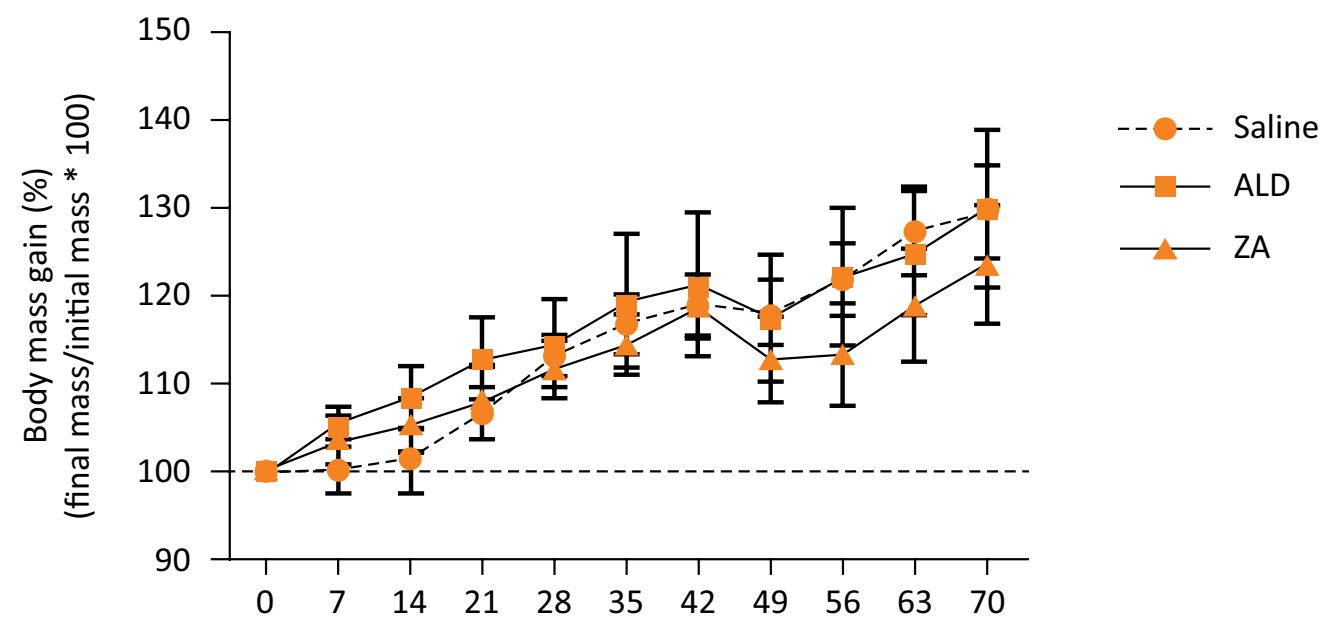

Figure 4 - Body mass variation of rats treated with saline, ALD or AZ and the semi-critical mandibular defect model. ${ }^{*} \mathrm{p}<0.05$, two-way ANOVA with repeated measures/Bonferroni test (mean $\pm \mathrm{SD}$ ).

\section{Evaluation of radiographic findings in rats undergoing mandibular defect model and treated with bisphosphonates}

Radiographic analysis showed a diffuse radiolucent area in the control group with well-defined edges on the control side and total tissue repair on the Mucograft ${ }^{\circledR}$ side. In AG, a radiolucent lesion with irregular edges in the mandibular ramus was observed on both sides, but smaller on the Mucograft ${ }^{\circledR}$ side. A radiolucent lesion with irregular edges was observed on both sides in the $Z G$, but a discrete radiopaque marker was observed (Fig. 3).

Treatment with Mucograft ${ }^{\circledR}$ modifies local inflammatory infiltrate profile; however, it does not reduce histological aspects of ONJ

Histologically, the results were similar. Total bone neoformation was observed in the CG treated with Mucograft ${ }^{\circledR}$ when compared to the control side (empty osteocyte lacunae $=13.2 \pm 0.5 \%$ in saline and $11.0 \pm 2.3 \%$ in Mucograft $^{\circledR}$ sides). Inflammatory cells were absent in Mucograft ${ }^{\circledR}(0.0 \pm 0.0$ cells $)$ and light in Control side (0.2 \pm 0.1$)$. Intense inflammatory infiltrate was observed in the $A G$ and $Z G$ on the control sides $(86.7 \pm 23.7$ and $85.0 \pm 17.3$ cells, respectively) associated with delayed bone repair and devitalized bone tissue $(42.9 \pm 4.3 \%$ and $46.8 \pm 10.7 \%$ empty osteocyte lacunae, respectively).

On the Mucrograf ${ }^{\circledR}$ side, a discrete inflammatory infiltrate $(30.7 \pm 10.5$ cells) was also associated with delayed bone repair and devitalized bone tissue, respectively. The use of the Mucograft ${ }^{\circledR}$ collagen matrix accelerated bone repair in the $\mathrm{CG}$ and reduced imaging signs of ONJ in the AG $(48.1 \pm 5.6 \%$ empty osteocyte lacunae) and ZG (41.1 $\pm 5.3 \%$ empty osteocyte lacunae), without affecting delayed bone repair and ONJ, respectively (Fig. 5). 


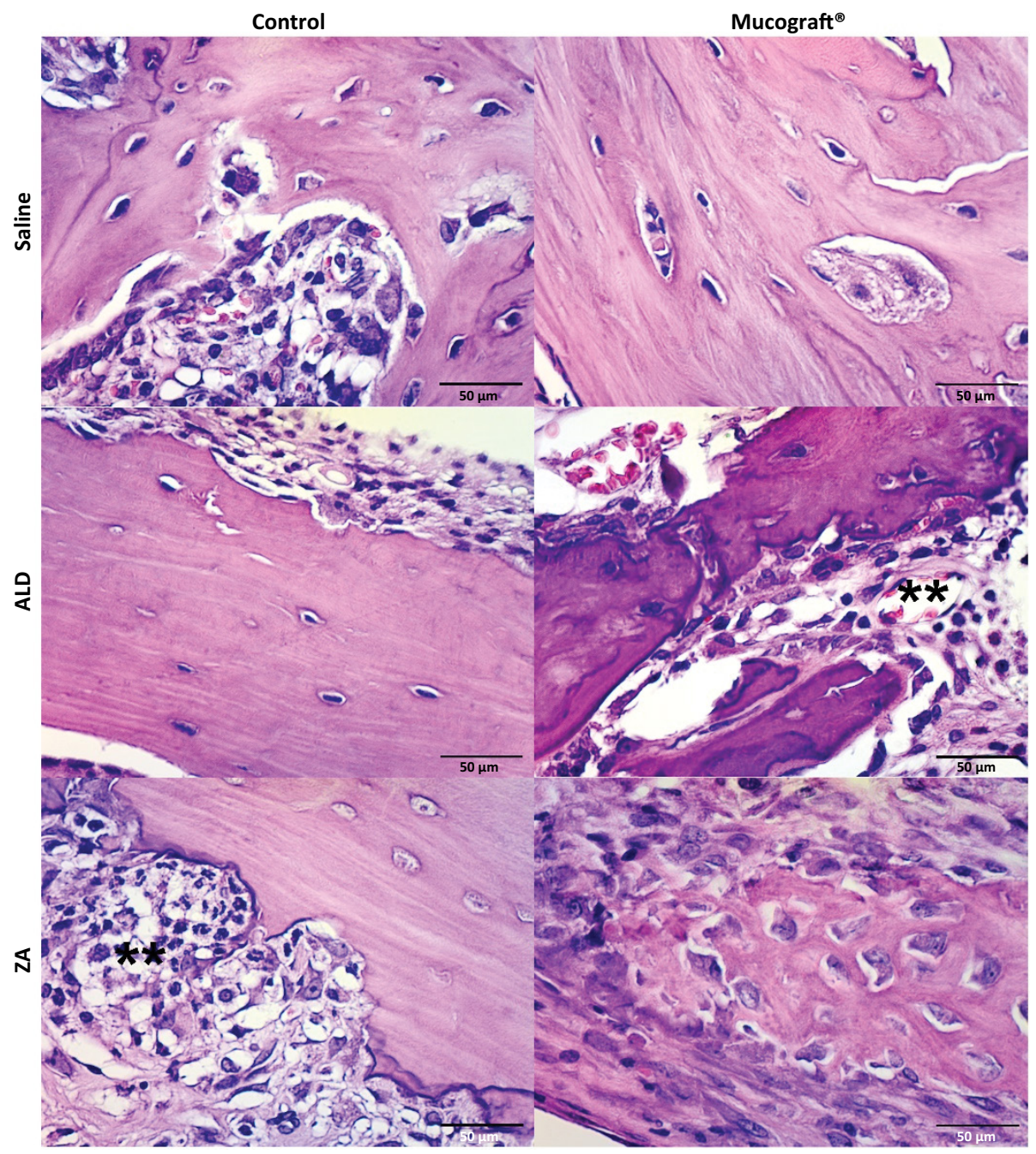

Figure 5 - Microscopic analysis of the mandible of rats treated with saline, AZ or ALD, and critical mandibular defect model treated with or without Mucograft ${ }^{\circledR}(\mathrm{HE}, \mathrm{x} 400)$. **Inflammatory infiltrate.

The percentage of empty osteocyte lacunae was significantly increased in the AG $(42.9 \pm 4.3 \%)$ and ZG $(46.8 \pm 10.7 \%)$ when compared to the group treated with saline solution $(13.2 \pm 0.5 \%)$, both for the animals in the control group $(p=0.025)$ and animals with the Mucograft $^{\circledR}$ collagen matrix $(48.1 \pm 5.6 \%, 41.1 \pm 5.3 \%$ and $11.0 \pm 2.3 \%$, respectively) ( $p=0.003$ ). There was no significant difference between the percentage of viable osteocyte lacunae between the Control and Mucograft groups treated with saline $(p=0.269), A L D(p=0.540)$ and ZA ( $p=0.732$ ) (Table 1).

The $A G$ and $Z G$ showed an increase in the number of polymorphonuclear cells when compared to the group treated with saline solution, both on the control side $(p=0.004)$ and the Mucograft ${ }^{\circledR}$ side $(p<0.001)$. However, on the Mucograft ${ }^{\circledR}$ side, the number of polymorphonuclear cells was significantly lower in the animals treated with ALD $(p=0.035)$ and those treated with ZA ( $p=0.034)$ (Table 1).

There was no difference in mononuclear cell count between the experimental groups ( $p>0.05)$. However, the $A G$ and $Z G$ showed a significant increase in the number of inflammatory cells in relation to the saline group on the control side $(p<0.001)$ and the Mucograft ${ }^{\circledR}$ side $(p<0.001)$. Mucograft ${ }^{\circledR}$ membrane implantation significantly reduced the number of inflammatory cells in the animals treated with ALD $(p=0.026)$ and those treated with ZA ( $p=0.005)$ (Table 1$)$. 
Table 1 - Cellular profile of the mandible of rats treated with saline, ALD or AZ and the semi-critical mandibular defect model treated with or without Mucograft ${ }^{\circledR}$.

\begin{tabular}{|c|c|c|c|c|}
\hline & \multicolumn{3}{|c|}{ Experimental group } & \multirow[b]{2}{*}{$\mathbf{p}-\mathbf{V}=$ value } \\
\hline & Saline & AG & ZG & \\
\hline \multicolumn{5}{|c|}{ Empty osteocyte lacunae (\%) } \\
\hline Control & $13.2 \pm 0.5$ & $42.9 \pm 4.3^{*}$ & $46.8 \pm 10.7 *$ & 0.025 \\
\hline Mucograft $\circledast$ & $11.0 \pm 2.3$ & $48.1 \pm 5.6^{*}$ & $41.1 \pm 5.3^{*}$ & 0.003 \\
\hline p-value ${ }^{b}$ & 0.269 & 0.540 & 0.732 & \\
\hline \multicolumn{5}{|c|}{ Osteoclasts (n) } \\
\hline Control & $2.0 \pm 1.5$ & $2.7 \pm 1.2$ & $1.8 \pm 0.7$ & 0.842 \\
\hline Mucograft $\circledast$ & $2.0 \pm 0.9$ & $2.5 \pm 0.5$ & $3.0 \pm 1.7$ & 0.829 \\
\hline p-value ${ }^{b}$ & 1.000 & 0.892 & 0.523 & \\
\hline \multicolumn{5}{|c|}{ Apoptotic osteoclasts (\%) } \\
\hline Control & $0.0 \pm 0.0$ & $22.5 \pm 13.1$ & $62.5 \pm 21.6^{*}$ & 0.036 \\
\hline Mucograft $\circledast$ & $0.0 \pm 0.0$ & $33.3 \pm 20.1$ & $62.6 \pm 18.5^{*}$ & 0.034 \\
\hline p-value ${ }^{b}$ & 1.000 & 0.722 & 1.000 & \\
\hline \multicolumn{5}{|c|}{ Neutrophil polymorphonuclear } \\
\hline Control & $0.2 \pm 0.1$ & $44.3 \pm 12.5^{*}$ & $41.6 \pm 14.0 *$ & 0.004 \\
\hline Mucograft $®$ & $0.0 \pm 0.0$ & $16.7 \pm 5.4^{*}$ & $18.6 \pm 1.6^{*}$ & $<0.001$ \\
\hline p-value ${ }^{b}$ & 1.000 & 0.035 & 0.034 & \\
\hline \multicolumn{5}{|c|}{ Mononuclear (n) } \\
\hline Control & $0.0 \pm 0.0$ & $15.7 \pm 8.1$ & $16.5 \pm 10.2$ & 0.446 \\
\hline Mucograft $\circledast$ & $0.0 \pm 0.0$ & $14.0 \pm 8.0$ & $19.8 \pm 5.9$ & 0.071 \\
\hline p-value ${ }^{b}$ & 1.000 & 0.925 & 0.777 & \\
\hline \multicolumn{5}{|c|}{ Inflammatory cells $(n)$} \\
\hline Control & $0.2 \pm 0.1$ & $86.7 \pm 23.7 *$ & $85.0 \pm 17.3 *$ & $<0.001$ \\
\hline Mucograft $\Re$ & $0.0 \pm 0.0$ & $30.7 \pm 10.5^{*}$ & $38.4 \pm 5.4^{*}$ & $<0.001$ \\
\hline p-value ${ }^{b}$ & 1.000 & 0.026 & 0.005 & \\
\hline
\end{tabular}

${ }^{a}$ ANOVA/Bonferroni test; ' tudent's $t$-test; ${ }^{*} p<0.05$ vs. saline; ${ }^{\dagger} p<0.05$ vs. ALD (mean \pm SEM) AG - alendronic group; ZG - zoledronic group.

\section{Discussion}

The pathophysiology of ONJ is multifactorial. The lack of treatment options highlights the medical and scientific inability to define the most prevalent causality. Bisphosphonates inhibit osteogenic cells, restricting angiogenesis, and have a negative effect on endothelial cells that compromises the healing of the oral mucosa ${ }^{10-12}$. Under these circumstances, the soft tissues are unable to cover the surgical wound, maintaining bone exposure, which worsens the inflammatory condition ${ }^{10-13}$. Thus, the present study was conducted to evaluate a material that could improve the inflammatory response under these conditions.

The two most potent bisphosphonates are $A Z$ and $A L D^{14} . A Z$ is the treatment of choice for breast and metastatic prostate cancer and it is often associated with ONJ, which was used in this study due to its greater potency among bisphosphonates (20 times more potent than alendronic acid). Alendronate, on the other hand, is used orally to control and treat advanced osteoporosis and for that reason it was used as control and administered orally (by gavage) ) $^{14-15}$.

In this study, we investigated the effect of a collagen matrix to improve angiogenesis, epithelialization, and formation of bone sequestration in bisphosphonateinduced osteonecrosis. Various materials in the form of membranes have been tested to promote bone healing in patients with ONJ. The use of a platelet-rich plasma (PRP) membrane was proposed in a surgical protocol to reduce the occurrence of osteonecrosis in patients undergoing treatment with IV bisphosphonate who required extraction ${ }^{15}$. Bocanegra-Perez et al. ${ }^{16}$ 
observed accelerated angiogenesis around necrotic bone in rabbits combining vascular tissue and a single injection of PRP. In a study on rabbits, Aguirre and colleagues stated that the use of plasma rich in growth factors (PRGF) accelerates epithelialization and reduces inflammation in tongue wounds ${ }^{17}$. Our results using a collagen membrane showed similar results in which we observed a decrease in the inflammatory process with a decrease in polymorphonuclear cells in both groups where the collagen membrane was used.

One of the questions about PRP is the possibility of promoting infections because blood agar is used in microbiology to grow bacteria. Despite the similarity, PRP is not a different substrate from blood clots that naturally occur in wounds; thus, bacterial growth is expected to be similar to what occurs in any blood clot. In addition, the $\mathrm{pH}$ values of PRP vary between 6.5 and 6.7, comparatively more acidic than those of blood (7.0-7.2) and, therefore, we expect PRP to be less favorable for bacterial growth ${ }^{16}$. Another issue to be considered is the overexpression of growth factors and their receptors, associated with the tumor and in patients with dysplastic lesions, which suggests the possibility of inducing carcinogenesis or metastasis ${ }^{18}$. Therapeutic concentrates rich in growth factor could act as promoters (not initiators) of carcinogenesis, promoting the division and growth of mutant cells. However, it seems reasonable to avoid the use of PRP in patients with pre-cancerous oral lesions or with a history of oral squamous cell carcinoma. In these patients, based on the results, other types of materials such as the collagen membrane, which would decrease the inflammation present at the site, could be recommended.

Mucograft (MG) is a collagen matrix composed of type I and type III porcine collagen without chemical treatment. MG is bilayered with a thin and smooth compact layer composed of a low-porosity collagen framework and a porous layer with a noncompact, three-dimensional collagen framework. The efficacy of MG has primarily been assessed in terms of soft-tissue augmentation because of characteristics such as ease of handling, no requirement for preoperative hydration, and reduced chairside time ${ }^{19}$. Another histological finding revealed a favorable tissue reaction to MG with minimal inflammation and absence of multinucleated giant cells ${ }^{11}$, corroborating the findings in the present study of lower inflammation and the presence of multinucleated cells.

Based on the results, MG is an effective membrane that can be used in bone defects caused by osteonecrosis associated with bisphosphonates. The material is easy to use and manipulation does not present risk of infection and it can be used in association with other techniques.

\section{- Conclusions}

Mucograft is an effective membrane that can be used in bone defects caused by osteonecrosis associated with bisphosphonates. The material is easy to use and manipulate, has presented a minimal risk of infection and can also be used in association with other techniques.

\section{- References}

1. Schwartz HC. American association of oral and maxillofacial surgeons position paper on medication-related osteonecrosis of the jaw - 2014 Update and CTX. J Oral Maxillofac Surg. 2015;73:377. doi: 10.1016/j.joms.2014.10.035.

2. Voss PJ, Matsumoto A, Alvarado E, Schmelzeisen R, Duttenhöfer F, Poxleitner P. Treatment of stage II medication-related osteonecrosis of the jaw with necrosectomy and autologous bone marrow mesenchymal stem cells. Odontology. 2017;105:484-93. doi: 10.1007/ s10266-017-0295-4.

3. Miyashita H, Kameyama K, Morita M, Nakagawa T, Nakahara T. Three-dimensional radiologic-pathologic correlation of medication-related osteonecrosis of the jaw using 3D bone SPECT/CT imaging. Dentomaxillofacial Radiol. 2019;20190208. doi: 10.1259/dmfr.20190208.

4. Wang J, Goodger NM, Pogrel MA. Osteonecrosis of the jaws associated with cancer chemotherapy. J Oral Maxillofac Surg. 2003;61:1104-7. doi: 10.1016/S02782391(03)00328-8.

5. Williamson RA. Surgical management of bisphosphonate induced osteonecrosis of the jaws. Int J Oral Maxillofac Surg. 2010;39:251-5 doi: 10.1016/j.ijom.2009.11.014.

6. Steigenga JT, Al-Shammari KF, Nociti FH, Misch CE, Wang HL. Dental implant design and its relationship to longterm implant success. Implant Dent. 2003;12:306-17. doi: 10.1097/01.ID.0000091140.76130.A1.

7. Lazarovici TS, Mesilaty-Gross S, Vered I, Yahalom R, Taicher S, Yarom N. Serologic bone markers for predicting development of osteonecrosis of the jaw in patients receiving bisphosphonates. J Oral Maxillofac Surg. 2010;68:2241-7. doi: 10.1016/j.joms.2010.05.043.

8. De Barros Silva PG, Ferreira-Júnior $A E$, Teófilo $C R$, Barbosa MC, Lima-Júnior RCP, Sousa FB, Mota MRL, Ribeiro RA, Alves APNN. Effect of different doses of zoledronic acid in establishing of bisphosphonate-related osteonecrosis. Arch Oral Biol. 2015;60:1237-45. doi: 10.1016/j. archoralbio.2015.05.015.

9. Lim SS, Lee B, Kim IS, Hwang SJ. Differential modulation of zoledronate and etidronate in osseous healing of an extracted socket and tibia defect. Oral Surg Oral Med Oral Pathol Oral Radiol. 2017;123:8-19. doi: 10.1016/j. oooo.2016.08.009.

10. Paulo S, Laranjo M, Abrantes AM, Casalta-Lopes J, Santos $K$, Gonçalves AC, Paula AB, Marto CM, Sarmento-Ribeiro $A B$, Carrilho E, Serra A, Botelho MF, Ferreira MM. Synthetic calcium phosphate ceramics as a potential treatment for bisphosphonate-related osteonecrosis of the jaw. Materials (Basel). 2019;12. doi: 10.3390/ma12111840. 
11. Ramalingam S, Basudan A, Babay N, Al-Rasheed A, Nooh N, Nagshbandi J, Aldahmash A, Atteya M, Al-Hezaimi K. Efficacy of mucograft vs conventional resorbable collagen membranes in guided bone regeneration around standardized calvarial defects in rats: a histologic and biomechanical assessment. Int J Periodontics Restorative Dent. 2016;36 Suppl:s99-s107. doi: 10.11607/prd.2277.

12. George EL, Truesdell SL, Magyar AL, Saunders MM. The effects of mechanically loaded osteocytes and inflammation on bone remodeling in a bisphosphonateinduced environment. Bone. 2019;127:460-73. doi: 10.1016/j.bone.2019.07.008.

13. Kumar V, Sinha RK. Bisphosphonate related osteonecrosis of the jaw: an update. J Maxillofac Oral Surg. 2014;13:38693. doi: 10.1007/s12663-013-0564-x.

14. Oh JS, Kim SG. Collagen sponge and rhBMP-2 improve socket healing in rats treated with zoledronic acid. Braz Oral Res. 2017;31:e99. doi: 10.1590/1807-3107bor-2017. vol31.0099.

15. Sarkarat F, Motamedi MHK, Jahanbani J, Sepehri D, Kahali R, Nematollahi Z. Platelet-rich plasma in treatment of zoledronic acid-induced bisphosphonate-related osteonecrosis of the jaws. Trauma Mon. 2014;19:13-7. doi: 10.5812/traumamon.17196.

16. Bocanegra-Pérez $S$, Vicente-Barrero $M$, Knezevic $M$, Castellano-Navarro JM, Rodríguez-Bocanegra E, RodríguezMillares J, Pérez-Plasencia D, Ramos-Macías A. Use of platelet-rich plasma in the treatment of bisphosphonaterelated osteonecrosis of the jaw. Int J Oral Maxillofac Surg. 2012;41:1410-5. doi: 10.1016/j.ijom.2012.04.020.

17. Aguirre JI, Altman MK, Vanegas SM, Franz SE, BassitACF, Wronski TJ. Effects of alendronate on bone healing after tooth extraction in rats. Oral Dis. 2010;16:674-85. doi: 10.1111/j.1601-0825.2010.01677.x.

18. Martínez-González JM, Sánchez JC, Lafuente JCG, Trapero JC, Esparza Gómez GC, Lestón JMS. Existen riesgos al utilizar los concentrados de Plasma Rico en Plaquetas (PRP) de uso ambulatorio?. Med Oral. 2002;7:375-90.

19. Sanz M, Lorenzo R, ArandaJJ, Martin C, Orsini M. Clinical evaluation of a new collagen matrix (Mucograft $^{\circledR}$ prototype) to enhance the width of keratinized tissue in patients with fixed prosthetic restorations: a randomized prospective clinical trial. J Clin Periodontol. 2009;36:86876. doi: 10.1111/j.1600-051X.2009.01460.x.

\section{Correspondence:}

Rafael Linard Avelar

Rua Adolfo Gurgel, 133

60140120 Fortaleza - CE Brasil

Tel.: (55 85)99925-8858

rafael.linard@hotmail.com

Received: June 23, 2020

Review: Aug 19, 2020

Accepted: Sept 22, 2020
Conflict of interest: none

Financial source: none

This is an Open Access article distributed under the terms of the Creative Commons Attribution License, which permits unrestricted use, distribution, and reproduction in any medium, provided the original work is properly cited.

\begin{abstract}
${ }^{1}$ Research performed at School of Dentistry, Centro Universitário Christus (UNICHRISTUS), Fortaleza-CE, Brazil.
\end{abstract}

